J. Austral. Math. Soc. 21 (Series A) (1976), 1-4.

\title{
CHARLES ERNEST WEATHERBURN
}

\author{
F. GAMBLEN
}

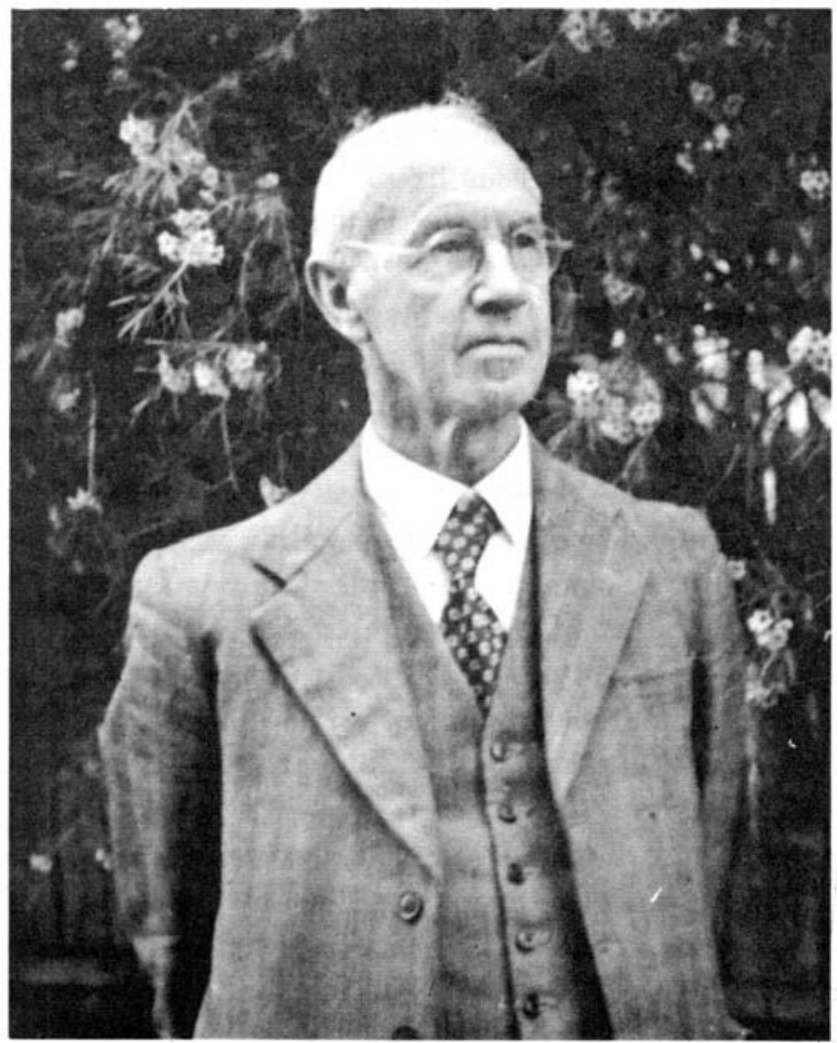

1884-1974

"I have received from Einstein himself a copy of his recent papers, and I shall always consider it an honour to have done so. But still I am at liberty to say that the theory does not impress me as holding the secret of the laws of nature. I feel much more disposed to trust the classical theory, modified perhaps so as to recognise the principle of equivalence. Einstein's theory is

\section{Copyright Australian Mathematical Society 1975}

Copyright. Apart from any fair dealing for scholarly purposes as permitted under the Copyright Act, no part of this JOURNAL may be reproduced by any process without written permission from the Treasurer of the Australian Mathematical Society. 
wonderful - wonderful in its complexity and in the mathematical difficulties overcome. Newton's is even more wonderful - wonderful in its simplicity and in its agreement with nearly all the experimental evidence of two and a half centuries. I cannot agree with those who would make nature more akin to the complex than to the simple."

So wrote Charles Ernest Weatherburn at Ormond College, Melbourne, in 1920. At this time Einstein's Theory of General Relativity was only 4 or 5 years old. Very few had taken the trouble to make a thorough study of it, most were willing to accept it on the strength of Einstein's reputation. The young Weatherburn, however, read practically all the accessible literature and applied his own vector methods in an endeavour to arrive at a decision on the theory. The above quotation gives us a good insight into the character of Weatherburn - a man who would not take a decision lightly, who would not be swayed by others simply because of their standing and reputation, and a man who firmly believed in the simplicity and goodness of life.

Charles Ernest Weatherburn was born on 18 June 1884. He graduated MA from Sydney in 1906 and proceeded to Trinity College, Cambridge as the holder of a major scholarship. He gained a first in the Mathematics Tripos in 1908 and took out his M.A. in 1915. One year later his alma mater recognised his mathematical work by awarding the D.Sc. At this time he was on the staff of Ormond College, Melbourne, which he left in 1923 to assume the chair of mathematics in Canterbury University College, Christchurch, New Zealand.

From the foundation of the University of Western Australia in 1913 until 1929 the subjects of mathematics and physics were administered in a joint department under one professorial head. In 1929 an independent department of mathematics was created and the University counted itself fortunate to attract such a distinguished figure as $\mathrm{C}$. E. Weatherburn to be the foundation professor of mathematics.

In the early depression years, Weatherburn was single-handed in the department and relied on assistance from the Physics department staff, Professor A.D. Ross, Dr. R. R. Nimmo and Mr. J. Shearer. From 1938 until his retirement in 1950, he and one lecturer were responsible for all the courses given in the department, yet in spite of his teaching and administrative commitments he continued with his original work and the writing of the books which have taken his name to all corners of the world. It would be impossible to number the mathematicians who learnt their vector geometry and differential geometry from his books.

In 1934 he was awarded the Hector Medal and Prize of the Royal Society of New Zealand for his outstanding original work, which was further recognised by the conferring in 1951 by Glasgow University of the Honorary degree of Doctor of Laws at its five hundredth anniversary. 
After retirement he and Mrs. Weatherburn continued to live in their home at Nedlands and he became a keen and active member of the local Bowling Club. From the time of the death of his wife in 1972 until a few days before his own death on 18 October 1974 he lived alone in the family home-always pleased to welcome for a cup of tea and a chat old students and friends who cared to drop in, and whether the call was early or late he was always as immaculately dressed as in his lecturing days.

For the present his name lives in the memory of those who were fortunate enough to be his students and who remember him as a man of kindly disposition, of moral integrity and possessing the gift of lucid exposition.

For the future his name is commemorated in his texts, in the Weatherburn Lecture Theatre of the Mathematics Building in the University of Western Australia, in the mathematics prize in his name and the students' Weatherburn Mathematical Society.

In 1966 Weatherburn was elected an honorary member of the Australian Mathematical Society, although unfortunately the Society was formed too late for him ever to take an active part in its affairs.

\section{PUBLICATIONS BY C. E. WEATHERBURN}

BOOKS

1921 Elementary vector analysis (Bell, London).

1924 Advanced vector analysis (Bell, London).

1927 Differential geometry. Vol. 1 (C. U. P.).

1929 Differential geometry. Vol. 2 (C. U. P.).

1938 Introduction to Riemannian Geometry and the Tensor Calculus (C. U. P.).

1946 First course in Mathematical Statistics (C. U. P.).

PAPERS

1914 'Boundary Problems for the Generalised Potential corresponding to the Equation $\nabla^{2} U-k^{2} U=0$, Quart. J. Pure Appl. Math. 46, 66-82.

1914 'The Mixed Boundary Problem for the Generalised Potential corresponding to the Equation $\nabla^{2} U-k^{2} U=0$, Ibid 83-94.

1914 'Singular Parameter Values in the Boundary Problems of the Potential Theory', Proc. Roy. Soc. Victoria 27 (New Series), 164-178.

1915 'Green's Functions for the equation $\nabla^{2} U-k^{2} U=0$, and the Integration of some related equations', Quart. J. Pure Appl. Math. 46, 198-215.

1915 'Vector Integral Equations of the First Kind', Ibid 46, 339-355.

1915 'Note on my paper "Green's Functions for the equation $\nabla^{2} U-k^{2} U=0$, etc."', Ibid 46, 384.

1915 'Problems in Electrostatics and the Steady Flow of Electricity under the Exponential Potential', Philos. Mag. (Ser. 6) 30, 568-581.

1916 'The application of Integral equations to Mathematical Physics', D. Sc. Thesis, Sydney University.

1916 'On certain Functions analogous to Harmonic Functions, and Oreen's Functions of any order for the equation $\nabla^{2} U-k^{2} U=0$ ', Quart. J. Pure Appl. Math. 47, 73-93. 
1916 'Vector Integral Equations and Gibb's Dyadics', Trans. Camb. Phil. Soc. 22 133-158.

1916 'On Two Fundamental Problems in the Theory of Elasticity', Philos. Mag. (Set. 6), 32, 15-38.

1916 'On the Equations of Equilibrium for an Elastic Isotropic Body, with or without Heredity', Messenger of Mathematics 46, 89-96.

1917 'A Plea for more general use of Vector Analysis in Mathematical Physics', Mathematical Gazette 9. 2-5.

1917 'On the Hydrodynamics of Relativity', Proc. Camb. Phil. Soc. 19, 72-85.

1917 'Some Theorems in Four-Dimensional Analysis', Quart. J. Pure Appl. Math. 48, 39-57.

1920 'Four-vector algebra and Analysis I, II', Messenger of Mathematics 49, 155-176.

1920 'The spectrum of learning', The Secondary Teacher, November 1920.

1920 'Vector Analysis in a University course', Math. Gaz. 10, 170-172.

1921

1923

1925

'Vector Algebra in General Relativity', Tôhoku Math. J. Ser. 1, 19, 89-104.

'Green's Dyadics in the Theory of Elasticity', Messenger of Mathematics 52, 136-156.

'On differential invariants in the Geometry of surfaces with some applications to Mathematical Physics', Quart. J. Pure Appl. Math. 50, 230-269.

1925 'On small deformations of surfaces and thin elastic shells', Quart. J. Pure Appl. Math. 50, 272-296.

1926 'Some new theorems in Geometry of a surface', Math. Gaz. 13, 1-6.

1926 'On triple systems of surfaces and non-orthogonal curvilinear coordinates', Proc. Roy. Soc. Edinburgh 46, 194-205.

1927 'On families of curves and surfaces', Quart. J. Pure Appl. Math. 50, 350-361.

1927 'On congruences of curves', Tôhoku Math. J. (Ser. 1) 27, 114-125.

1927 'On isometric systems of curves and surfaces', Amer. J. Math. 49, 527-534.

1927 'On small deformations of curves', Bull. Amer. Math. Soc. 33, 58-62.

1927 'Some properties of a family of curves on a surface', Proc. Edinburgh Math. Soc. 1, 160-165.

1927 'On Lamé families of surfaces', Ann. of Math. (Ser. 2) 28, 301-308.

1928 'On Levi-Cevita's Theory of Parallelism', Bull. Amer. Math. Soc. 34, 588-590.

1928 'On families of surfaces', Math. Ann. 99, 473-492.

1929 'On curvilinear congruences', Trans. Amer. Math. Soc. 31, 117-132.

1929 'On Weingarten surfaces', Math. Z. 29, 292-299.

1929 'On oblique trajectories of a family of curves on a surface', J. Reine Angew. Math. 160, 61-66.

1929 'On families of curves on a surface', Tôhoku Math. J. (Ser. 1) 29, 301-306.

1930 'On lines of equidistance of a family of surfaces', J. Math. Pure Appl. (Ser. 9) 9, 383-390.

1933 'The development of Multidimensional differential Geometry', ANZAAS, Report of the 21 st meeting of ANZAAS (August 1932), 12-28.

1933 'Some theorems in Riemannian geometry', Tôhoku Math. J. (Ser. 1) 38, 422-430.

1934 'On certain quadric hypersurfaces in Riemannian space', Proc. Edinburgh Math. Soc. 4, 85-91.

1937 'On motion of an extensible membrane in a given curved surface', Philos. Mag.(Ser.7) 23, 573-580.

1937 'On equations of Gauss and Codazzi for a surface', Tôhoku Math. J. (Ser. 1) 43, 30-32.

1937 'On certain useful vectors in differential geometry', Compositio Math. 4, 342-345.

1939 'On transverse vibrations of curved membranes', Philos. Mag. (Ser. 7) 28, 632-634.

\section{Department of Mathematics}

University of Western Australia

Nedlands, Perth. 